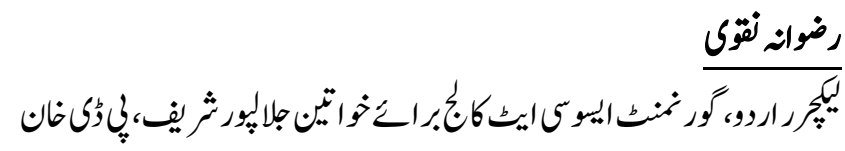

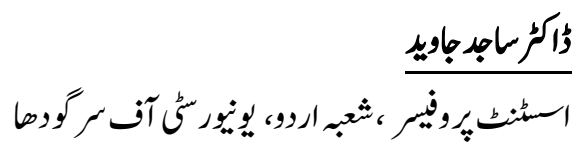

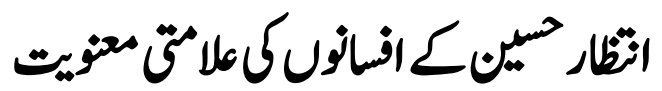

Rizwana Naqvi

Rizwana Naqvi, lecurer Urdu, GACW Jalal Pur Sharif, PD Khan.

Dr. Sajid Javeed

Assistant Professor, Department of Urdu, University of Sargodha.

\title{
Symbolic Ideality of Intazar Hussain's Short Stories
}

Intazar Hussain is a renowned short story writer in Urdu literature. In Urdu literature his writtings are at the vantage among great writers and their asset.His masterliness appears in his metaphorical and symbolic style of writing. His writings demand spacious study and deep view from his readers for its connoisseurship.His short stories emerge in simple incient narrative mode but holds a world of symbols and metaphors which can't be controled by common reader, therefore his art is particular and demands the mettle for its perception.His short stories specially presents four types of literary aspects, 1st social photography, 2nd romanticism and secularism where he narrats the stories about the declination of human and society, 3rd social and political issues and 4th aspect of his art is psychological where he discovers the human instinct and present it in diverse colours.Trough this article $\mathrm{i}$ have tried to enlighten his symbolic style of writting which confront in various forms.

Keywords: Metaphorical, sym6olism, particular art, social photography, romanticism, psychological aspects.

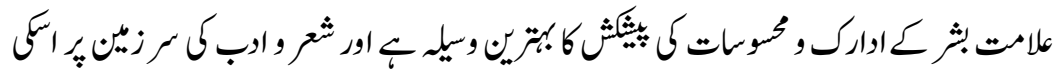

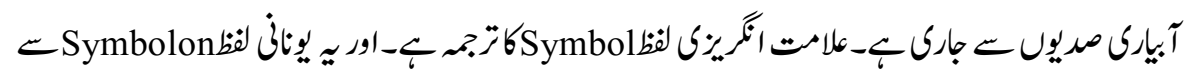

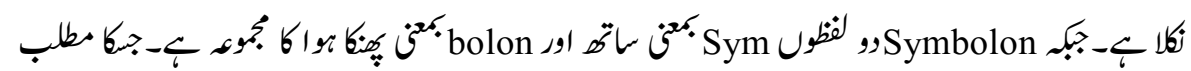




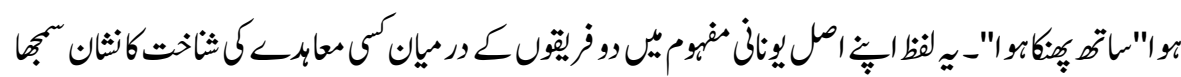

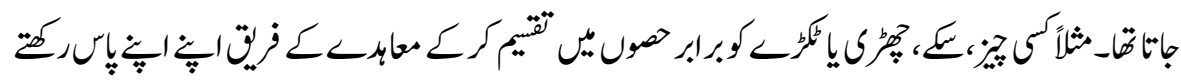

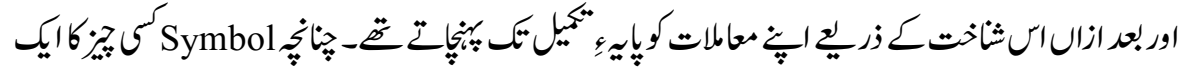

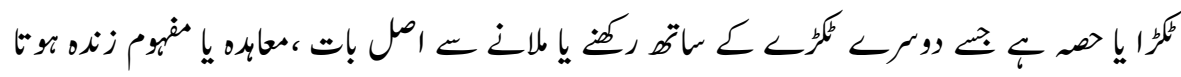

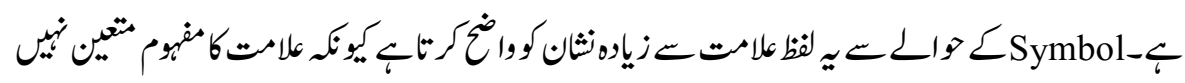

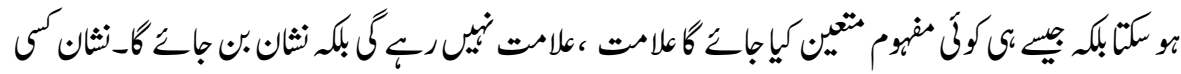

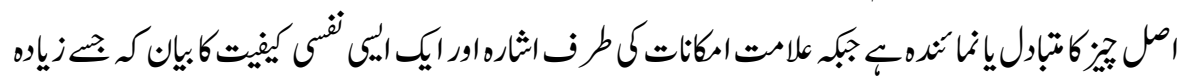

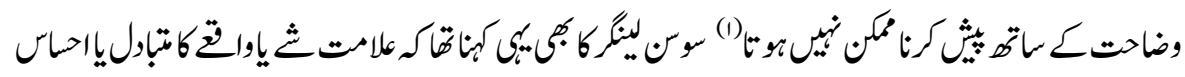

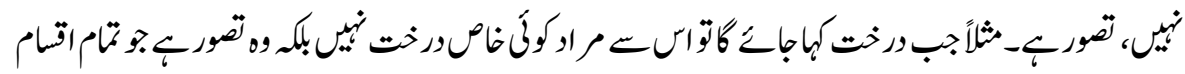

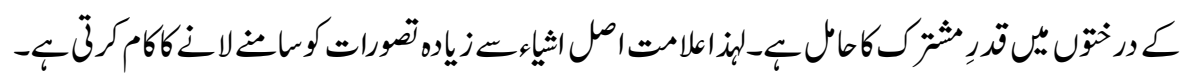

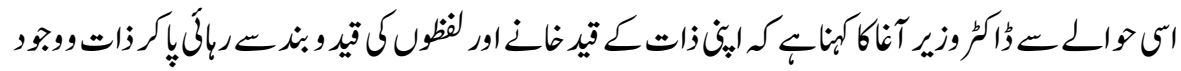

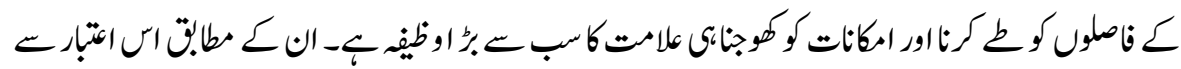

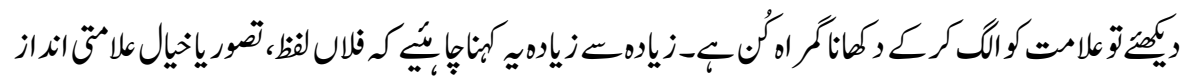

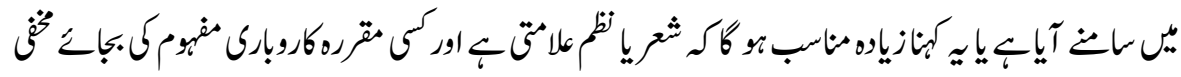

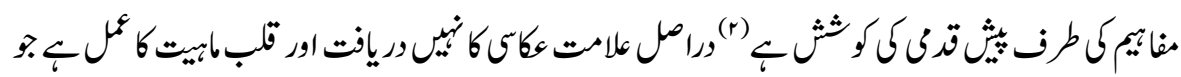

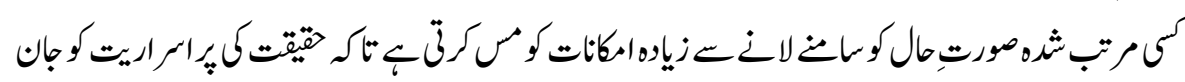

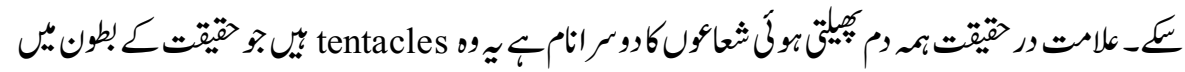

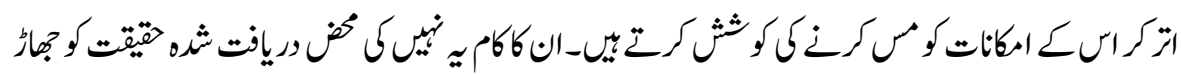

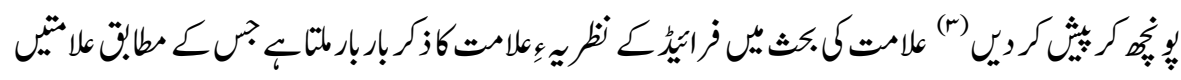

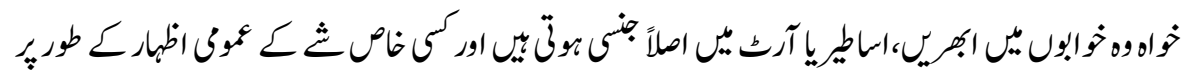

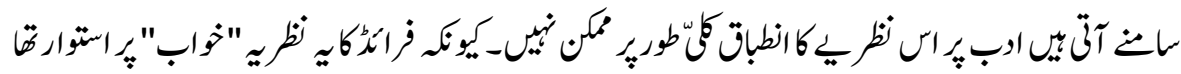

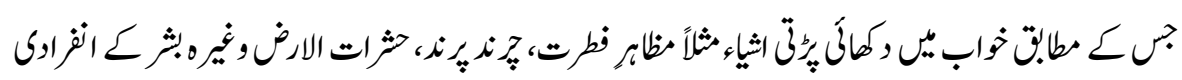
نجى لاشثورك ك نمانداه 


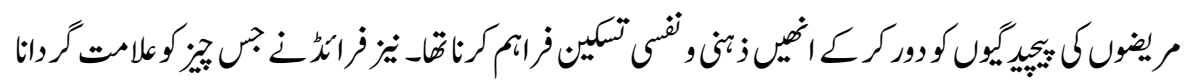

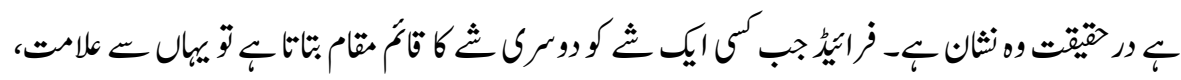

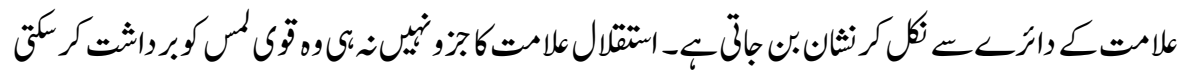

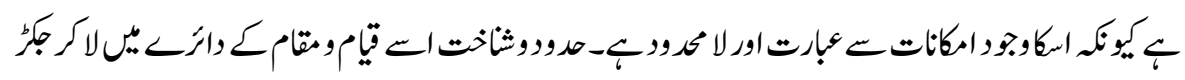

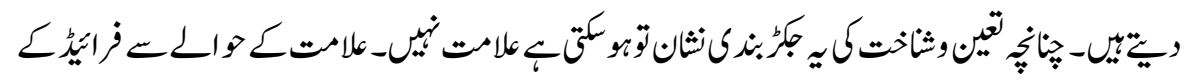

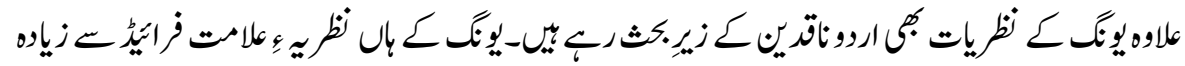

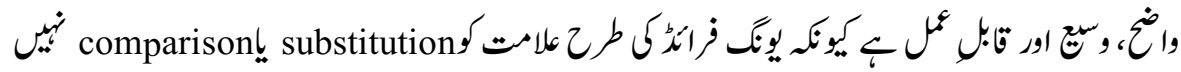

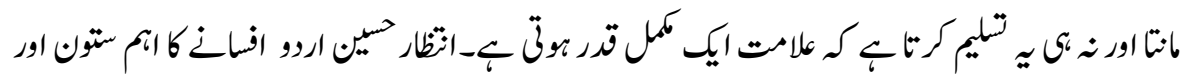

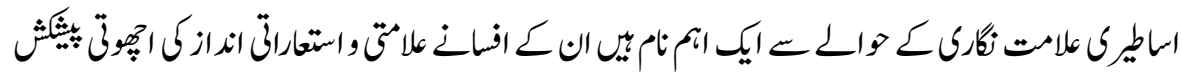

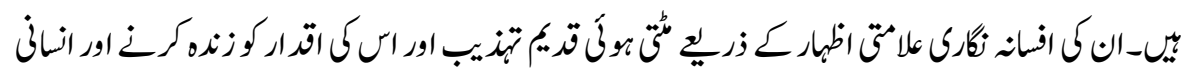

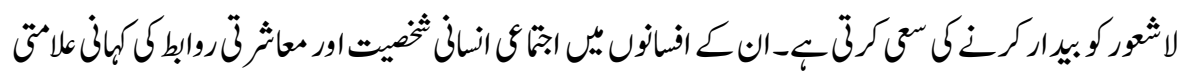

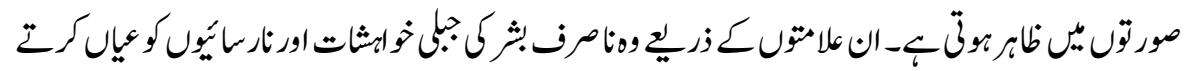

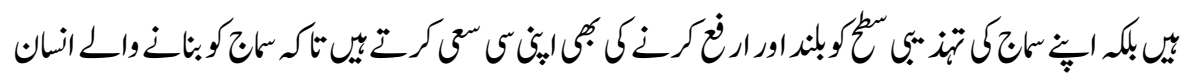

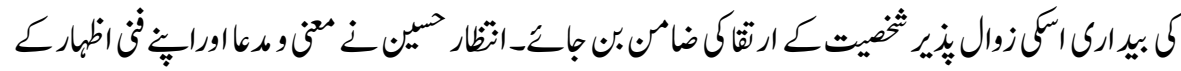

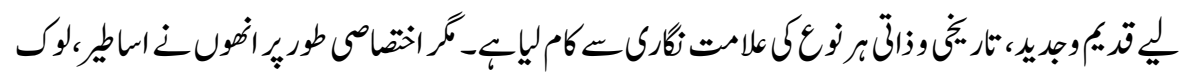

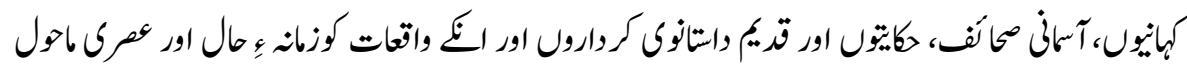

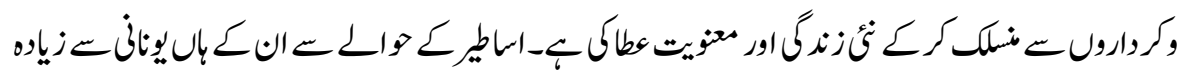

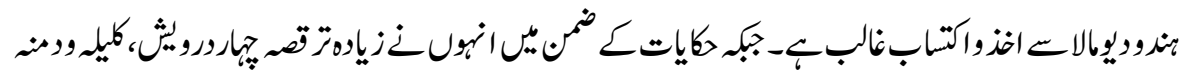

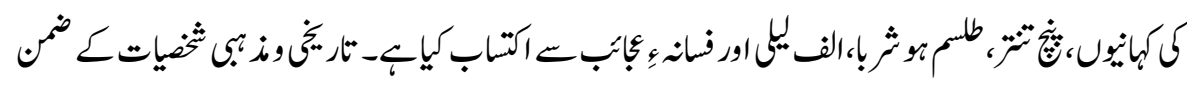

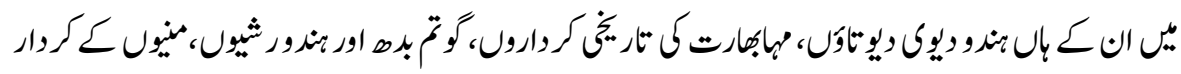

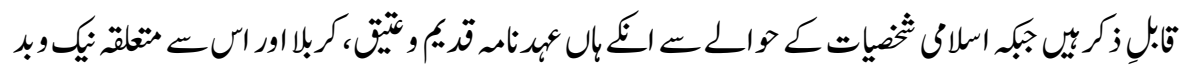

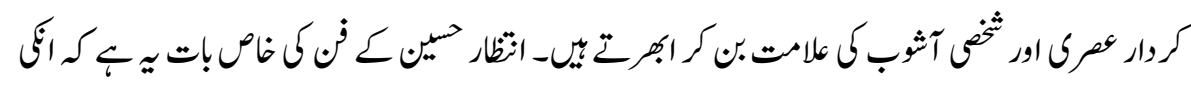




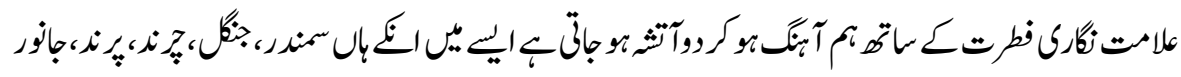

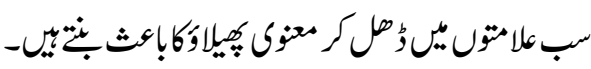

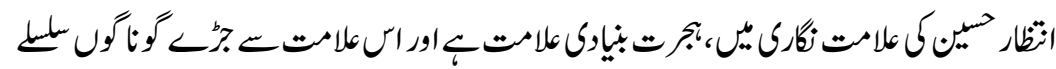

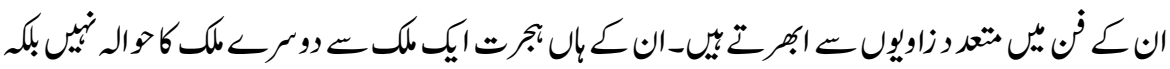

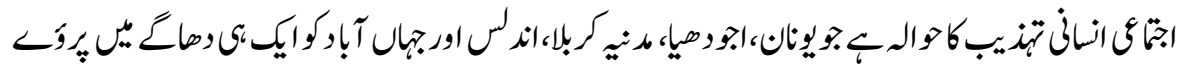

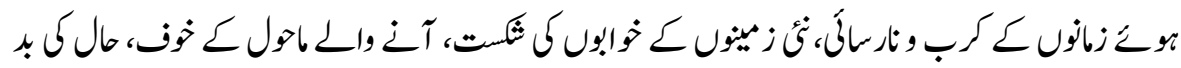

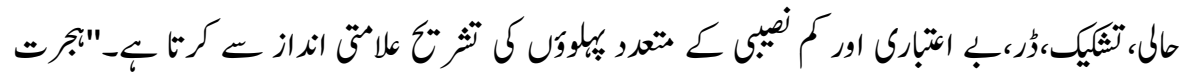

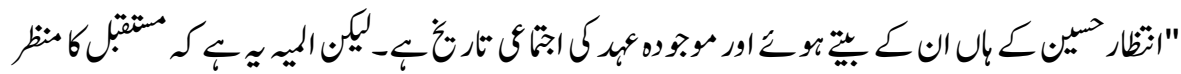

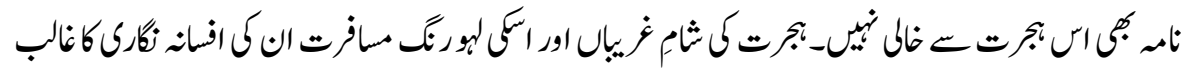

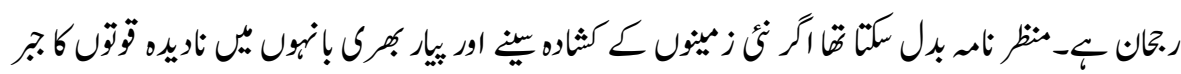

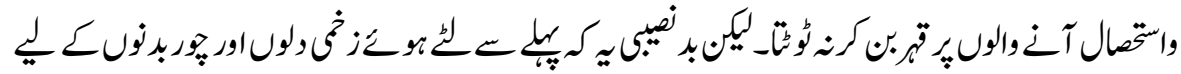

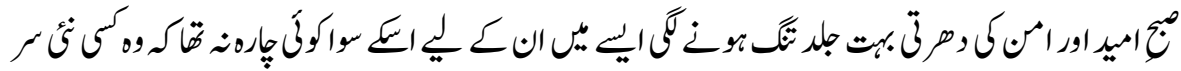

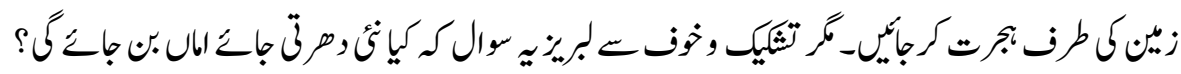

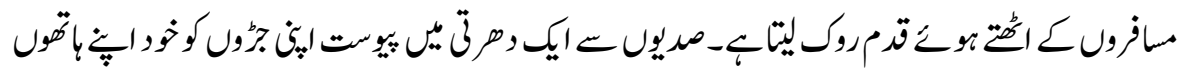

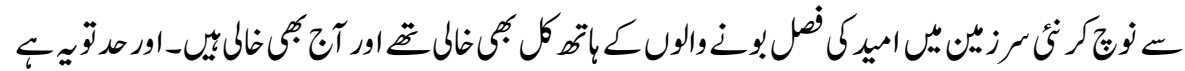

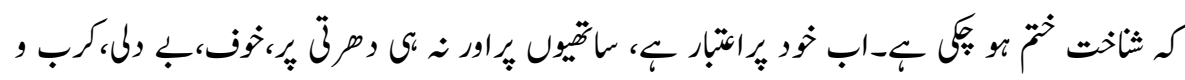

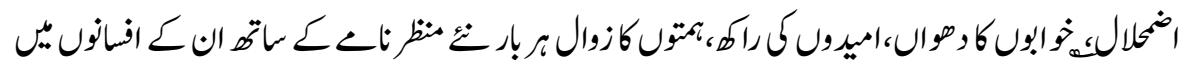

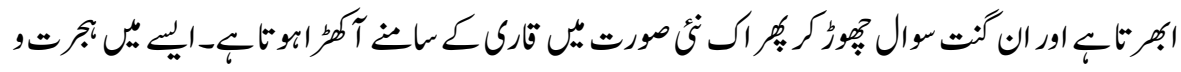

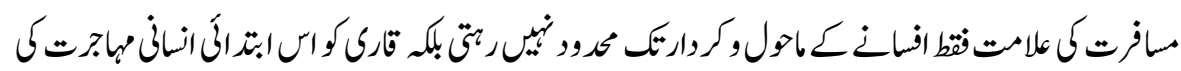

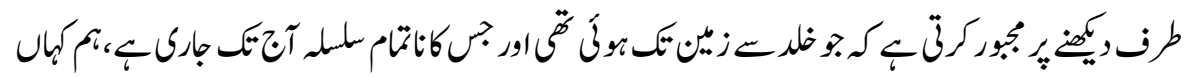

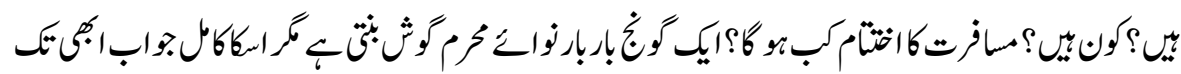

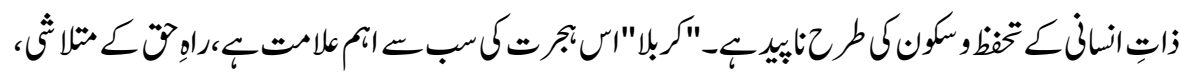

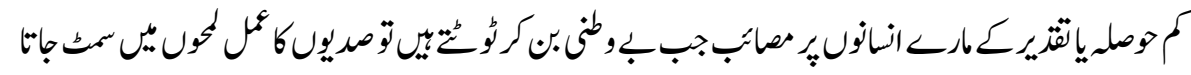




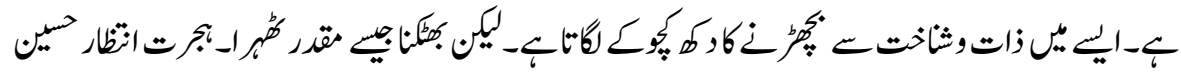

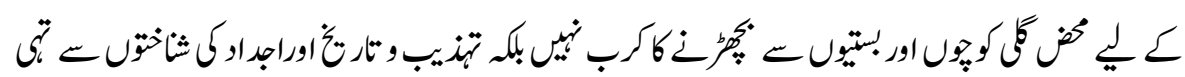

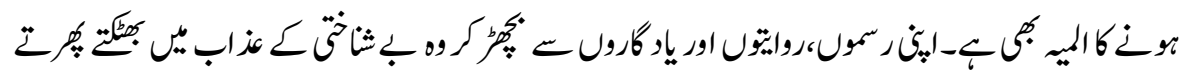
ب.

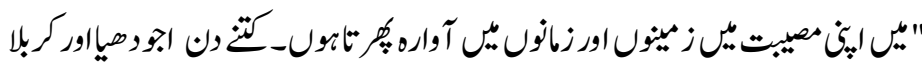

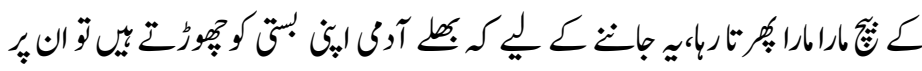

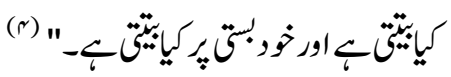

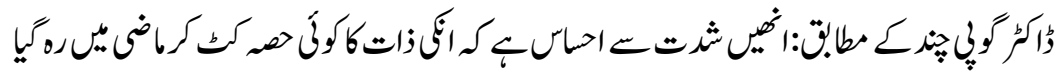

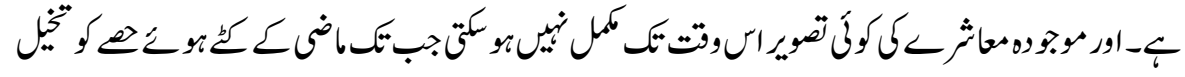

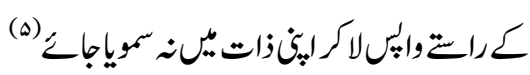

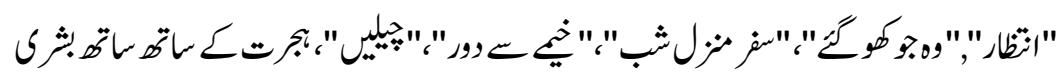

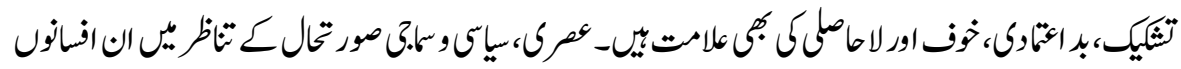

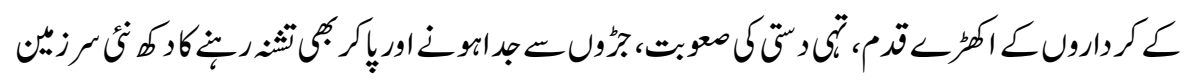

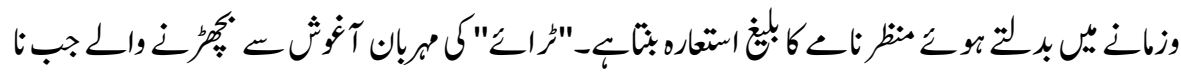

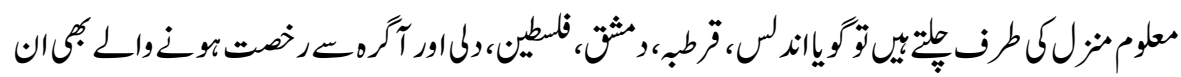

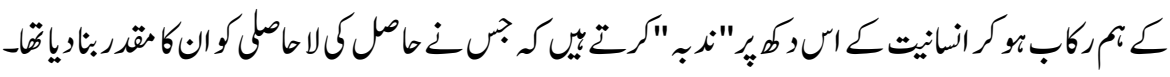

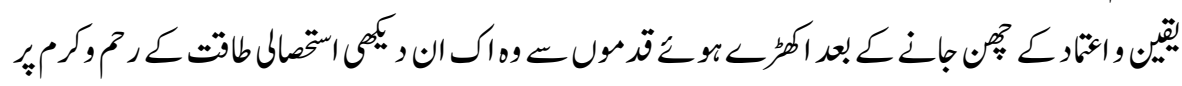

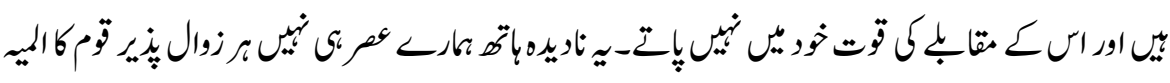

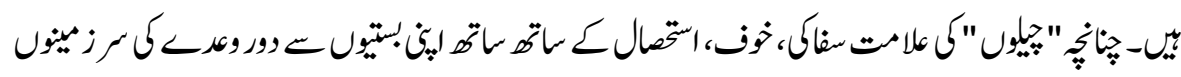

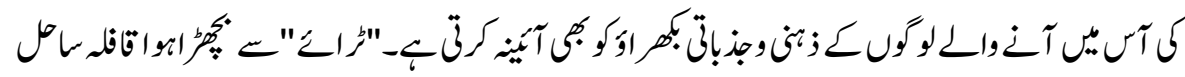

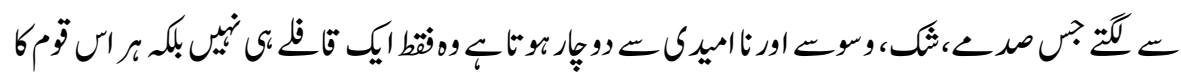

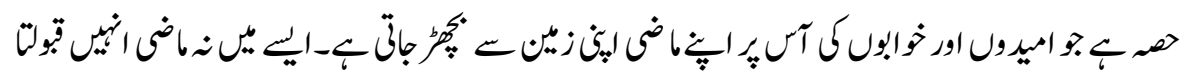

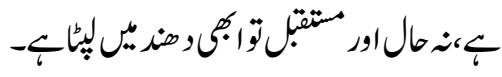




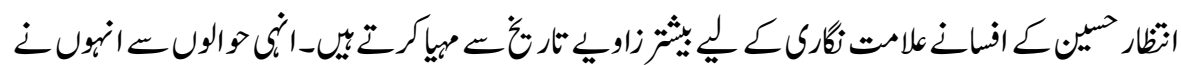

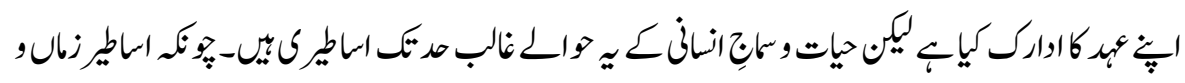

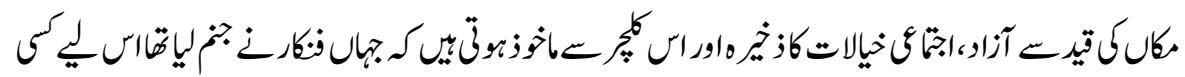

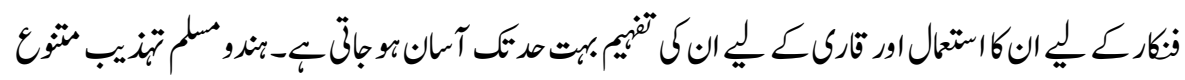

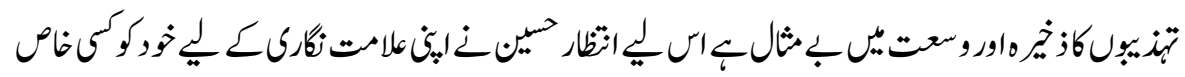

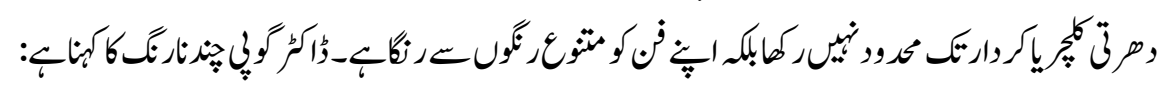

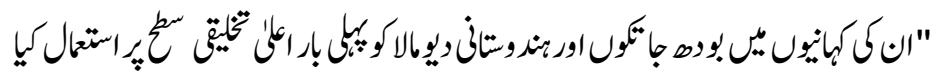

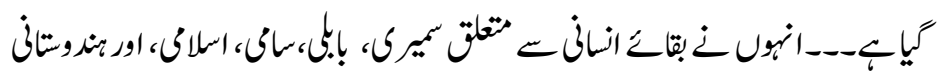

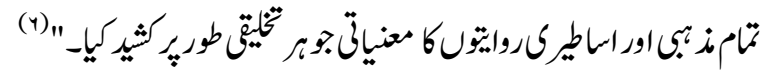

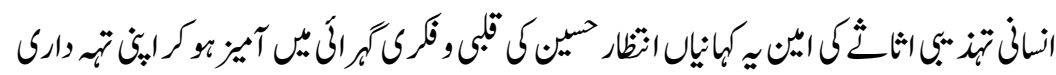

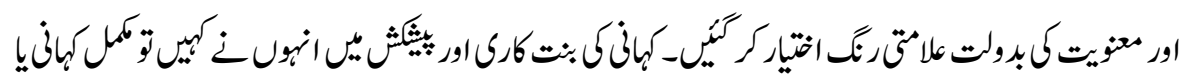

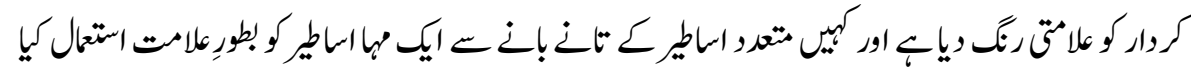

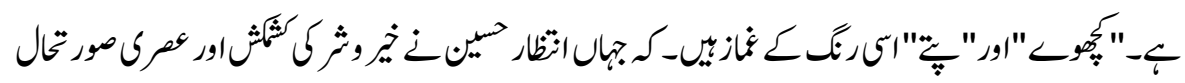

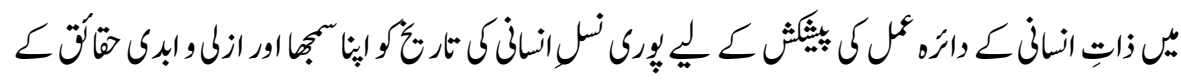

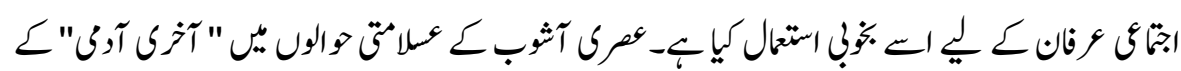

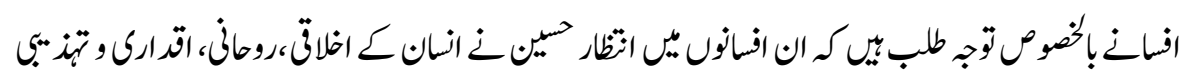

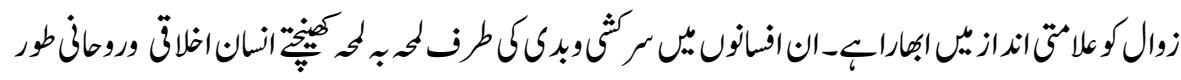

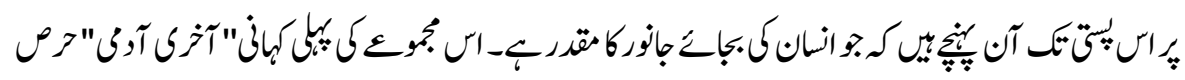

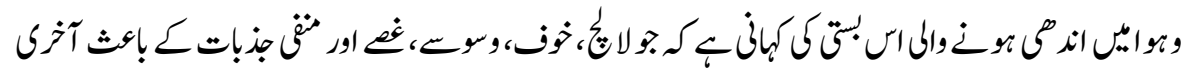

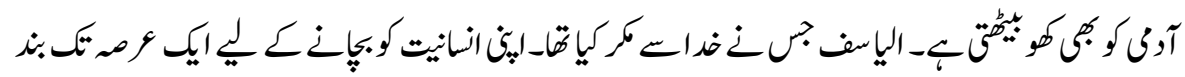
بان

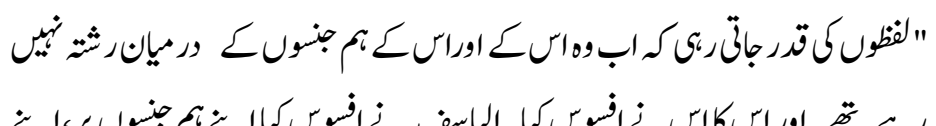

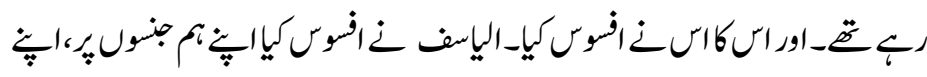




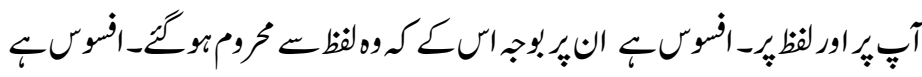

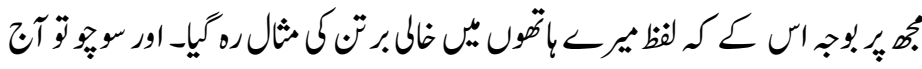

(c) (c)

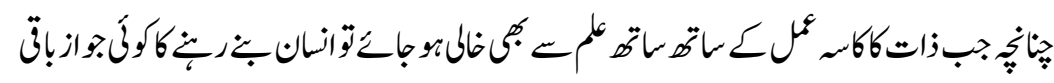

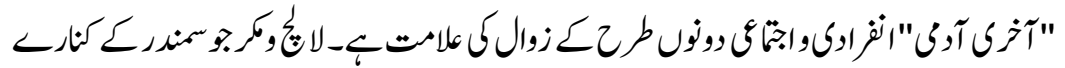

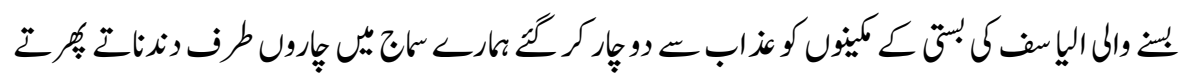

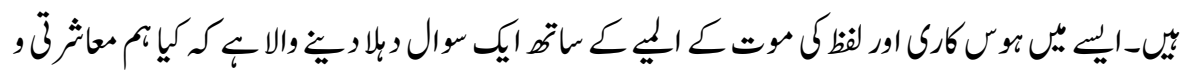

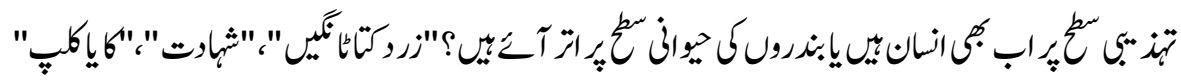

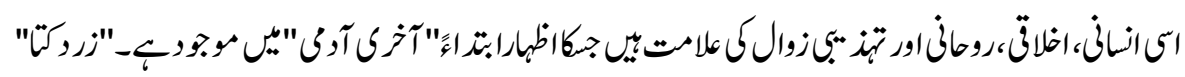

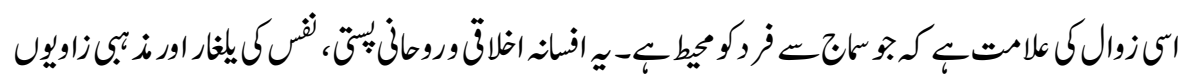

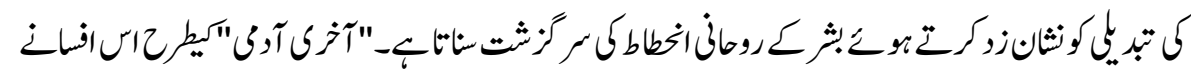

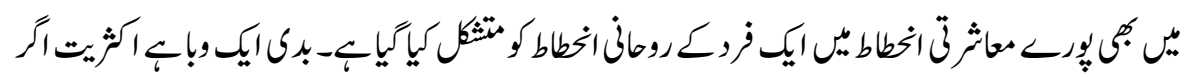

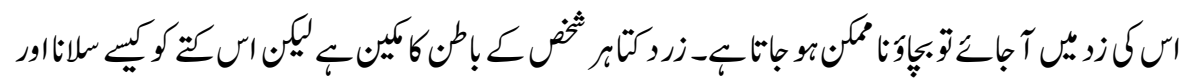

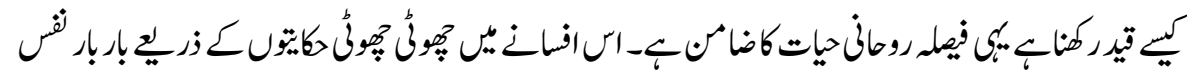

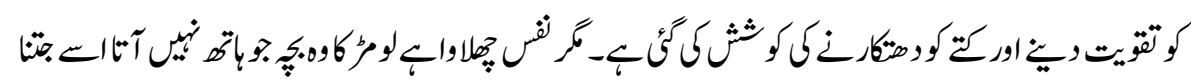

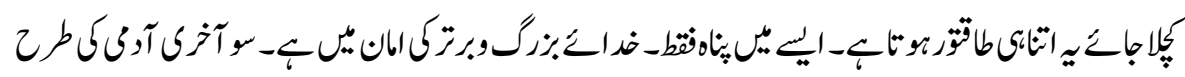

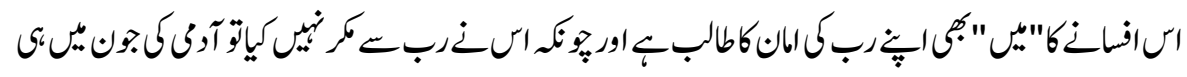

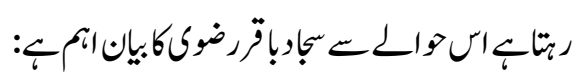

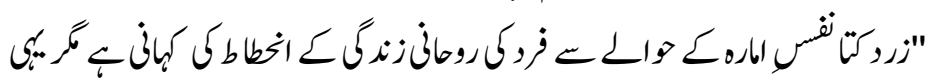

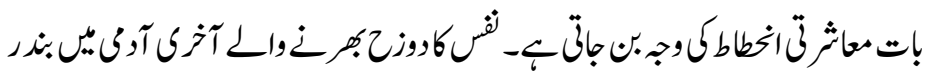

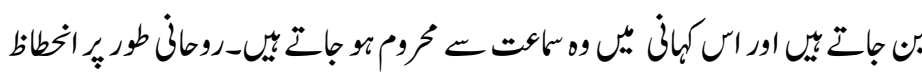

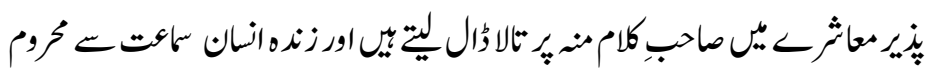




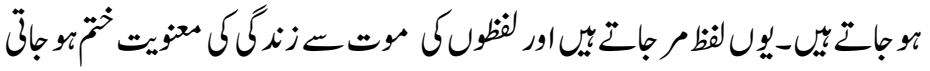

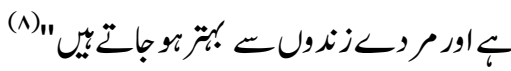

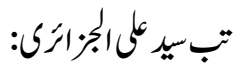

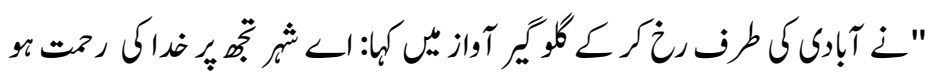

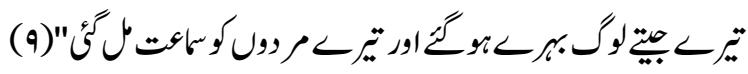

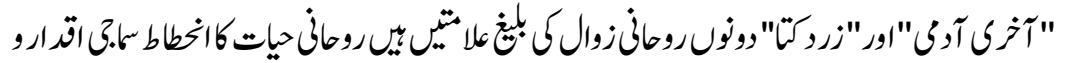

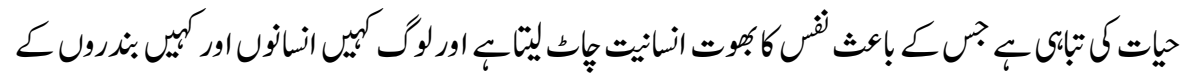

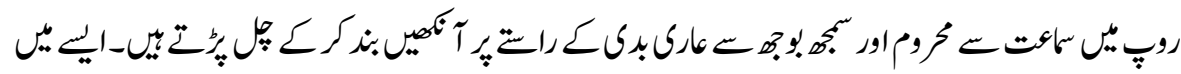

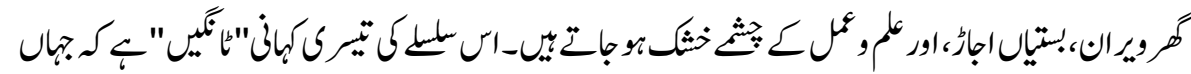

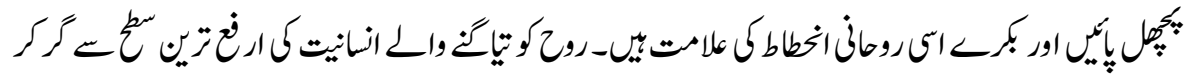

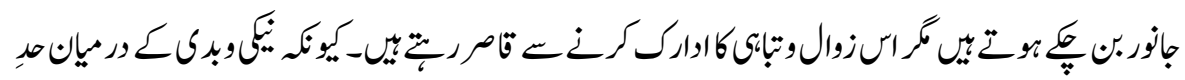

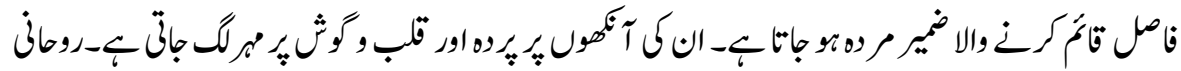

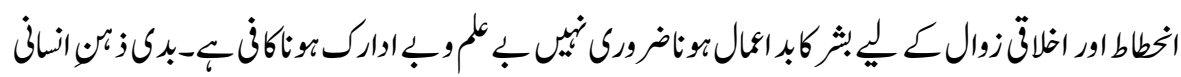

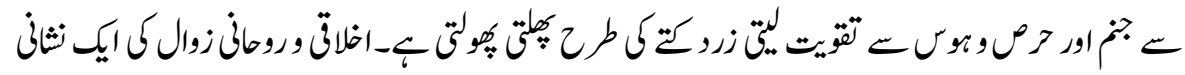

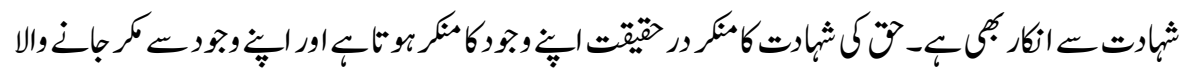

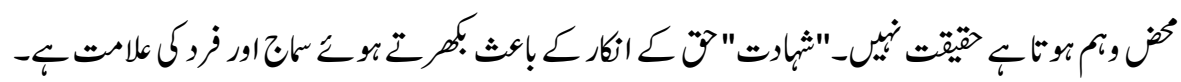

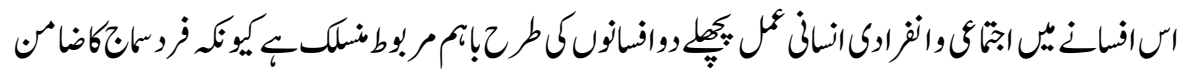

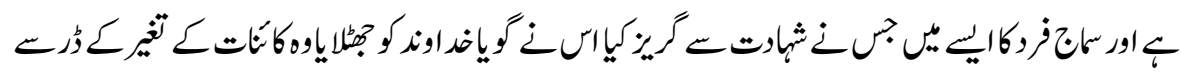

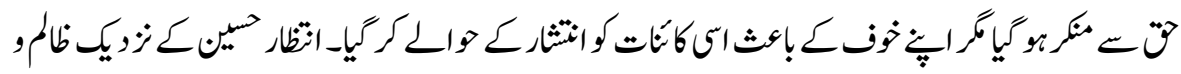

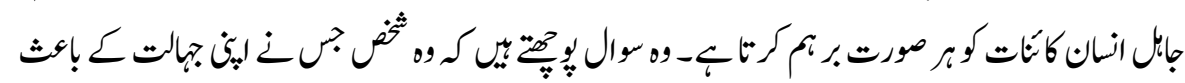

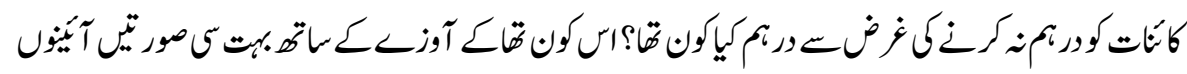

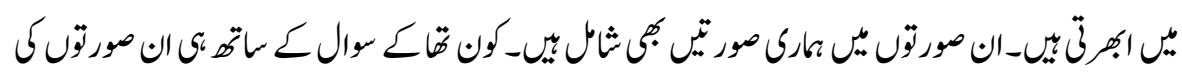

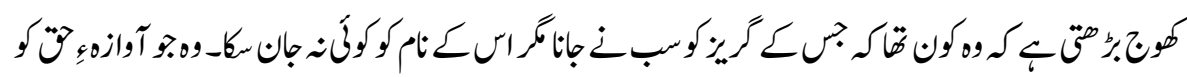




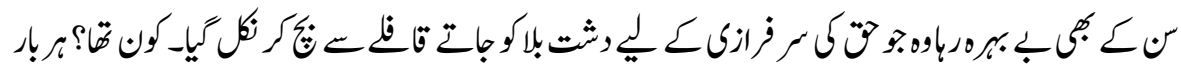

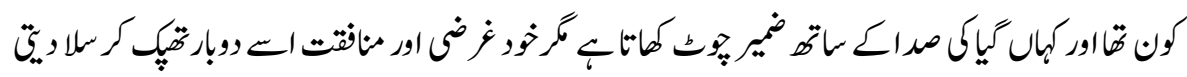

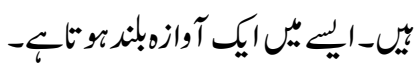

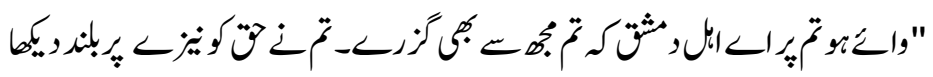

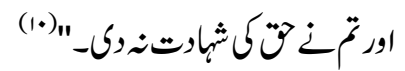

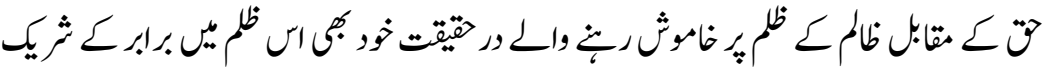

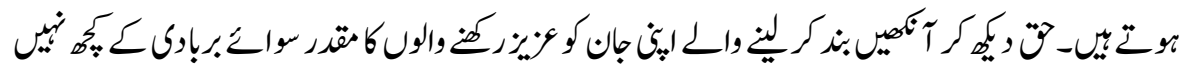

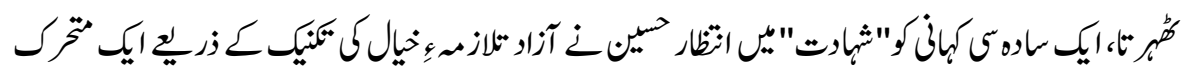

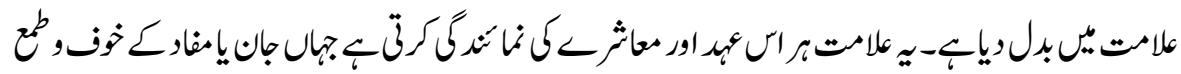

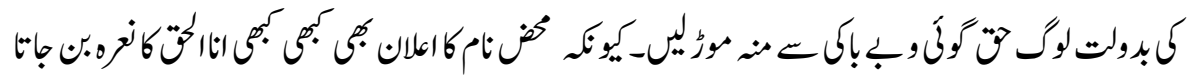

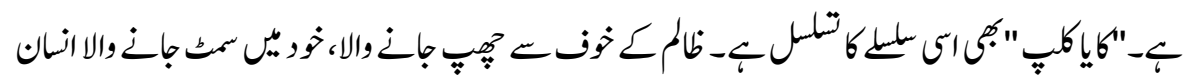

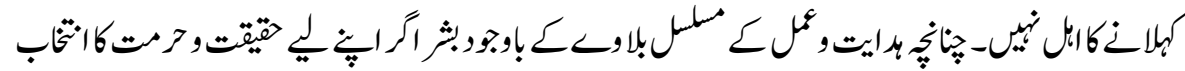

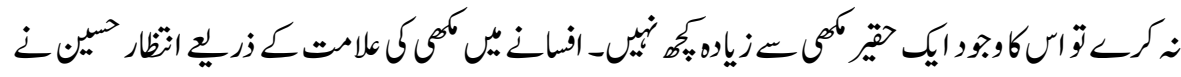

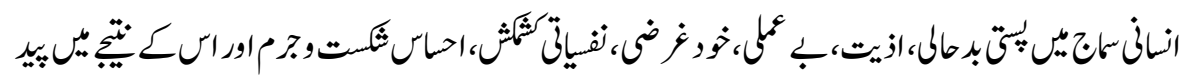

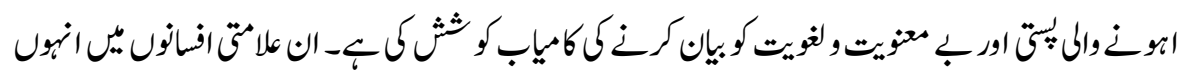

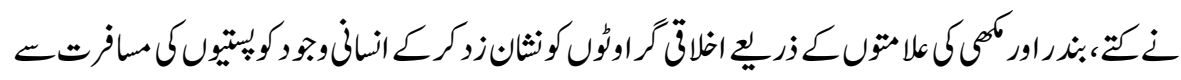

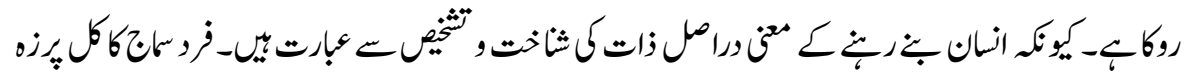

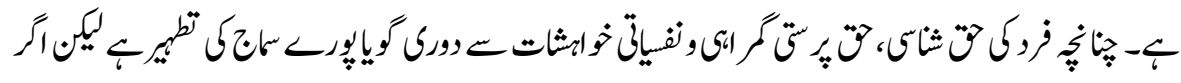

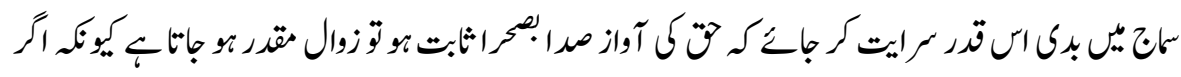

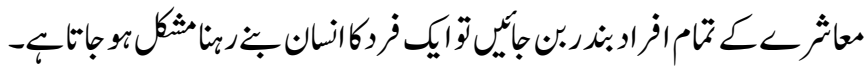

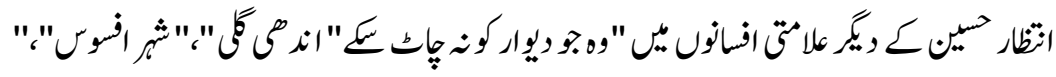

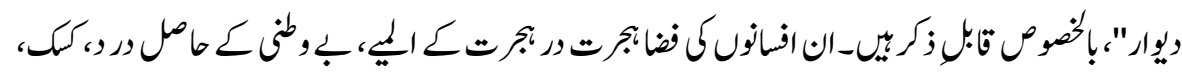

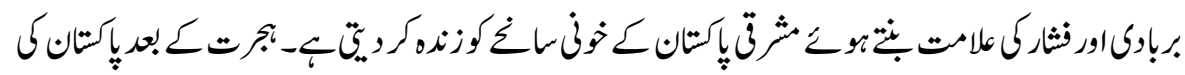




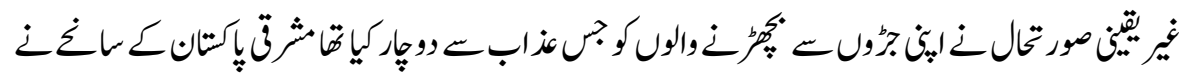

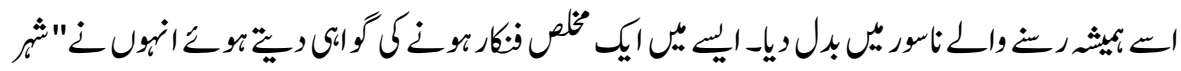

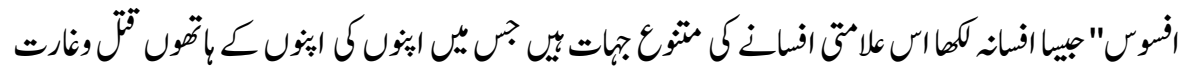

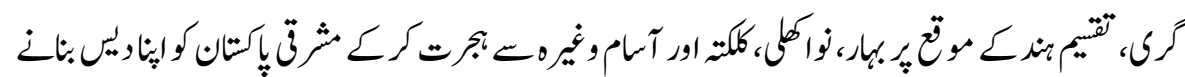

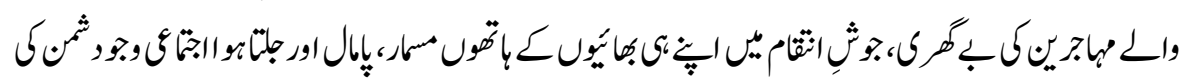

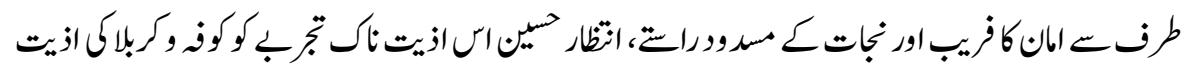

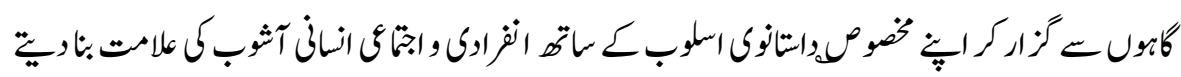

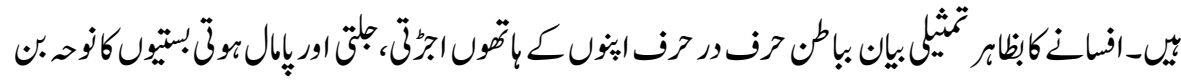

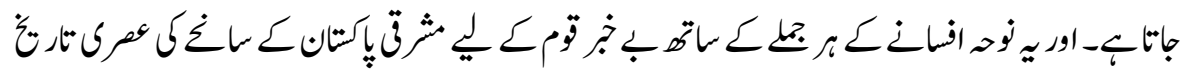

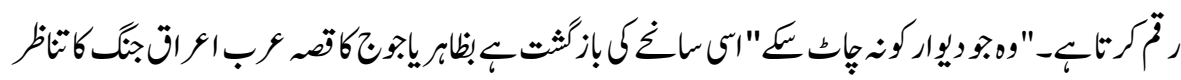

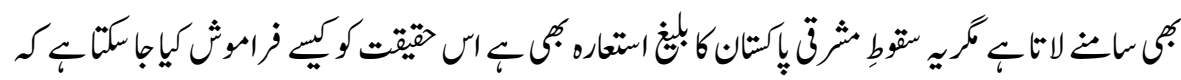

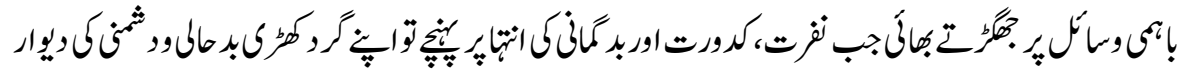

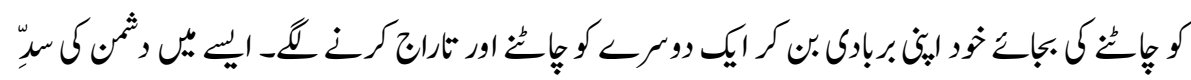

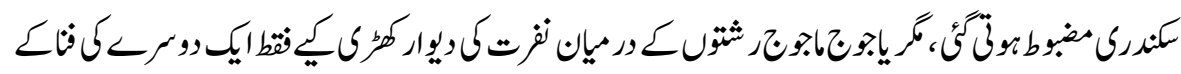

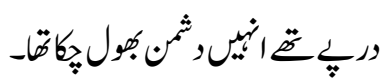

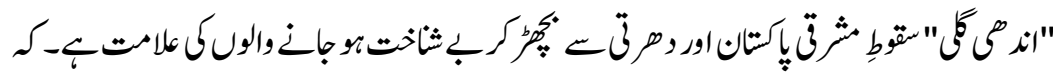

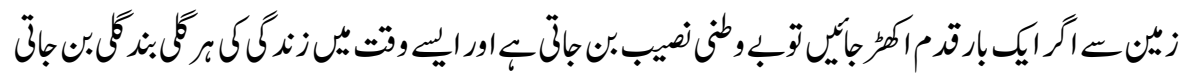

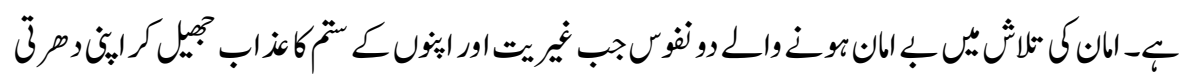

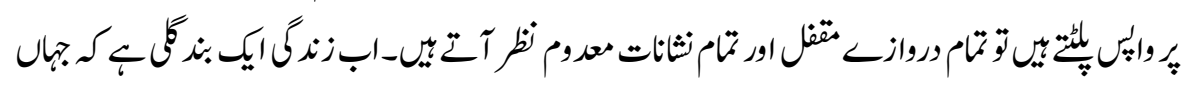

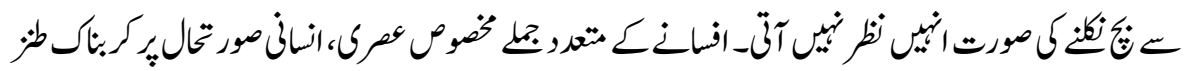

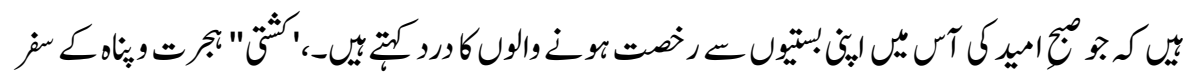

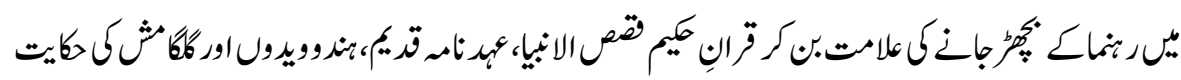

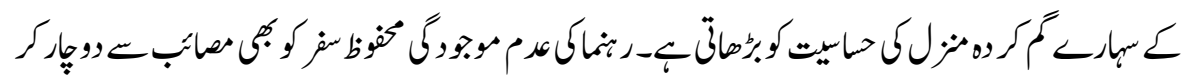




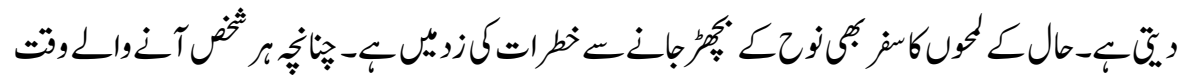

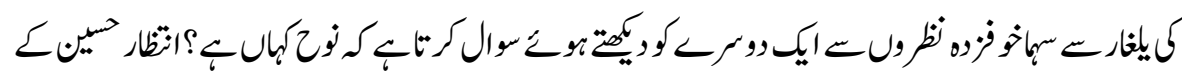

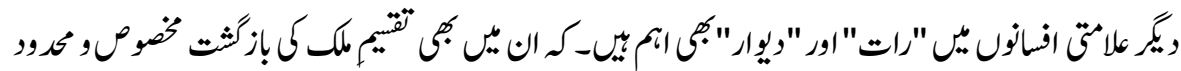

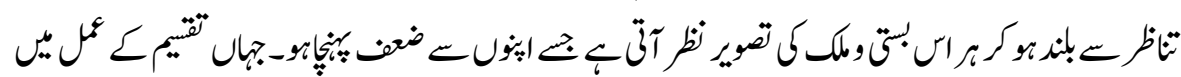

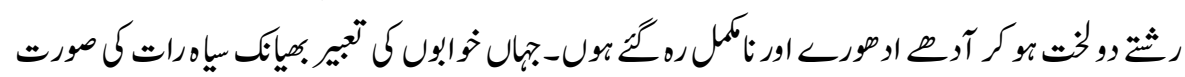

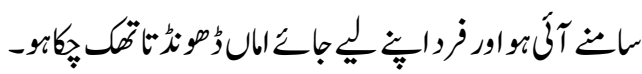

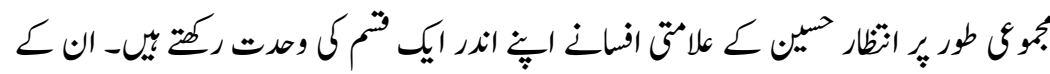

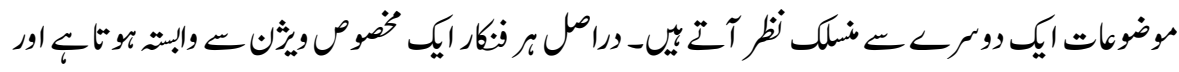

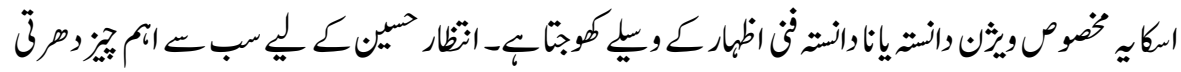

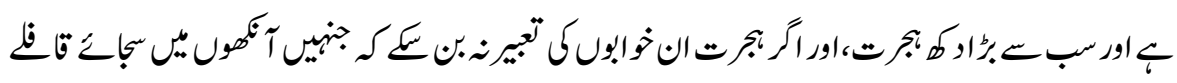

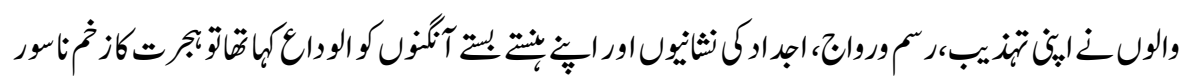

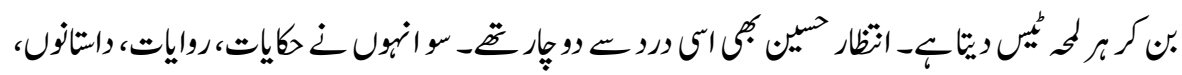

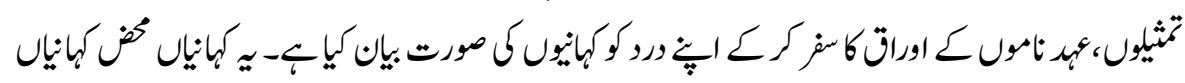

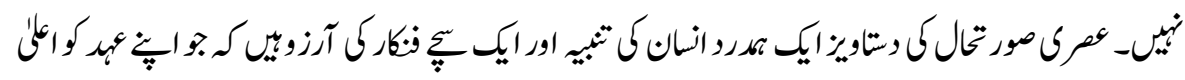

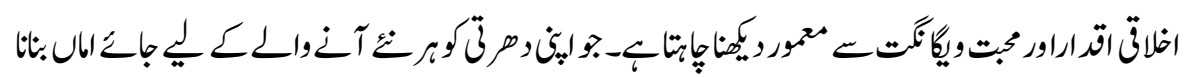

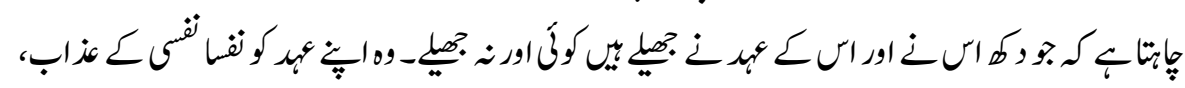

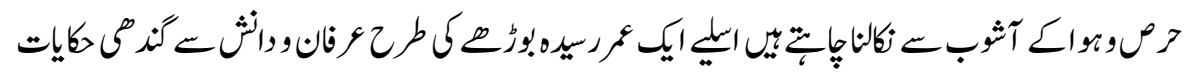

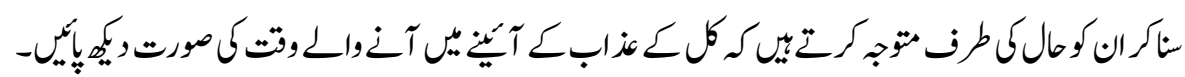

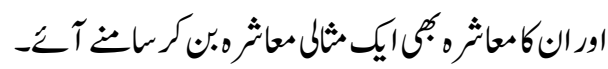

\section{والرجات}

1C.G Jung:symbols of transformation,1956,P-124(Routledge and kegan.

Paul.ltd-London. 


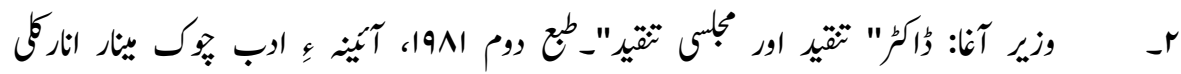

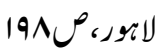

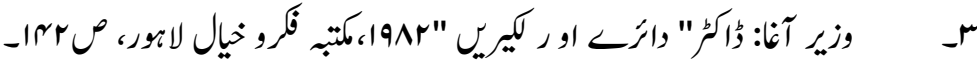

$$
\begin{aligned}
& \text { r }
\end{aligned}
$$

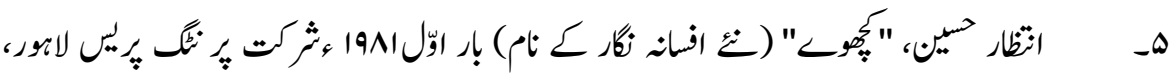

$$
1490
$$

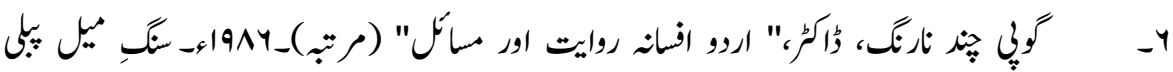

$$
\text { كيثز لانور، صLD-DYY }
$$

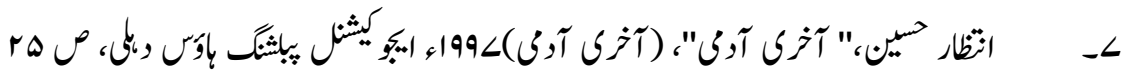

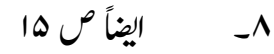

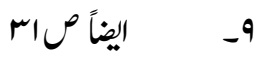

• إ- إيضاً ص مس" 